\title{
Noradrenergic $\beta$-Receptor Antagonism within the Central Nucleus of the Amygdala or Bed Nucleus of the Stria Terminalis Attenuates the Negative/Anxiogenic Effects of Cocaine
}

\author{
Jennifer M. Wenzel, Samuel W. Cotten, Hiram M. Dominguez, Jennifer E. Lane, Kerisa Shelton, Zu-In Su, and Aaron Ettenberg \\ Behavioral Pharmacology Laboratory, Department of Psychological and Brain Sciences, University of California, Santa Barbara, California 93106-9660
}

Cocaine has been shown to produce both initial rewarding and delayed anxiogenic effects. Although the neurobiology of cocaine's rewarding effects has been well studied, the mechanisms underlying its anxiogenic effects remain unclear. We used two behavioral assays to study these opposing actions of cocaine: a runway self-administration test and a modified place conditioning test. In the runway, the positive and negative effects of cocaine are reflected in the frequency of approach-avoidance conflict that animals develop about entering a goal box associated with cocaine delivery. In the place conditioning test, animals develop preferences for environments paired with the immediate/rewarding effects of cocaine, but avoid environments paired with the drug's delayed/anxiogenic actions. In the present study, these two behavioral assays were used to examine the role of norepinephrine (NE) transmission within the central nucleus of the amygdala (CeA) and the bed nucleus of the stria terminalis (BNST), each of which has been implicated in drug-withdrawal-induced anxiety and stressinduced response reinstatement. Rats experienced 15 single daily cocaine-reinforced $(1.0 \mathrm{mg} / \mathrm{kg}$, i.v.) runway trials $10 \mathrm{~min}$ after intracranial injection of the $\beta 1$ and $\beta 2 \mathrm{NE}$ receptor antagonists betaxolol and ICI 118551 or vehicle into the CeA or BNST. NE antagonism of either region dose dependently reduced approach-avoidance conflict behavior compared with that observed in vehicle-treated controls. In addition, NE antagonism selectively interfered with the expression of conditioned place aversions while leaving intact cocaine-induced place preferences. These data suggest a role for NE signaling within the BNST and the CeA in the anxiogenic actions of cocaine.

\section{Introduction}

Human cocaine users report feelings of intense pleasure that are in time displaced by anxiety, dysphoria, irritability, and craving (Anthony et al., 1989; Williamson et al., 1997). Such aversive properties of cocaine have also been demonstrated in animals (Rogerio and Takahashi, 1992; Blanchard and Blanchard, 1999; Ettenberg, 2004). Therefore, a full understanding of the factors underlying cocaine self-administration should include an assessment of how these dual and opposing actions of cocaine interact to alter an organism's drug-seeking motivation. Most researchers, however, have focused on the aversive effects of cocaine removal in drug-experienced animals (Koob and Le Moal, 1997; Smith and Aston-Jones, 2008), whereas the direct impact of cocaine's aversive/anxiogenic effects on drug-seeking in the naive animal, and the neuronal substrates mediating such effects, remain unclear.

Previously, we reported that animals traversing a straight alley for an intravenous injection of cocaine delivered upon goal-box

Received Sept. 9, 2013; revised Dec. 30, 2013; accepted Jan. 22, 2014.

Author contributions: J.M.W., Z.-I.S., and A.E. designed research; J.M.W., S.W.C., H.M.D., J.E.L., K.S., and Z.-I.S. performed research; J.M.W., S.W.C., K.S., and A.E. analyzed data; J.M.W. and A.E. wrote the paper.

This work was supported by the National Institute on Drug Abuse-National Institutes of Health (Grants DA005041 and DA033370 to A.E.). We thank Osnat Ben-Shahar for valuable methodological and conceptual contributions to this project.

Correspondence should be addressed to Aaron Ettenberg, PhD, Department of Psychological and Brain Sciences, University of California, Santa Barbara, CA 93106-9660. E-mail: ettenber@psych.ucsb.edu.

DOI:10.1523/JNEUROSCI.3861-13.2014

Copyright $\odot 2014$ the authors $\quad 0270-6474 / 14 / 343467-08 \$ 15.00 / 0$ entry develop over trials a unique behavior characterized by a rapid approach toward the goal, a stop at the entry threshold, and then an abrupt "retreat" back toward the start box (Ettenberg and Geist, 1991; Ettenberg, 2004). These retreats have been shown to reflect an approach-avoidance conflict stemming from the mixed positive and aversive effects of cocaine associated with the goal box (Ettenberg, 2004). Therefore, the operant runway provides a tool with which to explore the appetitive (approach) and the aversive (avoidance) qualities of cocaine in the same animal on the same trial. Of course, experimentally induced changes in approach-avoidance conflict behavior could occur by altering either or both of cocaine's dual effects. To address this, we used a modified conditioned place test that is sensitive to both the positive and negative actions of the drug. In this test, rats exhibit conditioned place preferences (CPP) for environments paired with the immediate/positive effects of intravenous cocaine, but conditioned place avoidance (CPA) of environments paired with the delayed/negative effects of the drug (Ettenberg et al., 1999).

In the present study, these two behavioral assays were used to examine the contribution to cocaine's anxiogenic effects of norepinephrine (NE) neurotransmission within two structures of the extended amygdala. Previous research has suggested a role for the central nucleus of the amygdala $(\mathrm{CeA})$ and the bed nucleus of the stria terminalis (BNST) in cocaine-induced approachavoidance conflict behavior (Wenzel et al., 2011). Both the CeA and BNST receive NE projections from the ventral noradrenergic bundle (Moore and Bloom, 1979), which has long been implicated in stress and anxiety (Itoi and Sugimoto, 2010), and acute 
stress increases NE activity within these structures (Pacak et al., 1995; Galvez et al., 1996). In addition, intra-BNST or intra-CeA administration of NE $\beta$-receptor antagonists reduces behavioral reactions to stressors (Cecchi et al., 2002a, 2002b), attenuates drug withdrawal-induced CPAs (Aston-Jones et al., 1999; Watanabe et al., 2003), and decreases stress-induced reinstatement of cocaineseeking behavior (Leri et al., 2002). We therefore hypothesized that NE neurotransmission within the CeA and/or BNST would play a role in the anxiogenic response to acute cocaine and, by extension, affect an organism's motivation to seek the drug.

\section{Materials and Methods}

Subjects. Subjects were 190 male albino Sprague Dawley rats (Charles River Laboratories) weighing 275-325 g at the time of surgery. Animals were pair housed in hanging plastic tubs in a temperature-controlled $\left(22^{\circ} \mathrm{C}\right)$ vivarium maintained on a $12 \mathrm{~h}$ light/dark cycle (lights on at $0800 \mathrm{~h}$ ). Subjects had ad libitum access to both food (Purina Rat Chow) and water throughout the duration of the experiment. All methods and procedures were conducted in strict adherence to the NIH Guide for the Care and Use of Laboratory Animals and were reviewed and approved by the University of California-Santa Barbara Institutional Animal Care and Use Committee.

Surgery. Animals were gentled through daily handling for $7 \mathrm{~d}$ before surgery. Surgical procedures were conducted as described previously (Wenzel et al., 2011). Briefly, rats were deeply anesthetized with an intramuscular injection of ketamine and xylazine (56.25 and $7.5 \mathrm{mg} /$ $\mathrm{kg}$, respectively; Abbott Laboratories) and fitted with an indwelling intravenous catheter $(13 \mathrm{~mm}$ of polyethylene tubing, $0.3 \mathrm{~mm}$ inner diameter, $0.64 \mathrm{~mm}$ outer diameter; Dow Corning). Catheters were inserted into the right jugular vein, secured in place by silk sutures, and subcutaneously passed to a threaded cannula (catalog \#313G; Plastics One) attached to Mersilene surgical mesh (Bard) that exited though a 2 $\mathrm{mm}$ hole on the animal's back. All animals were also fitted with bilateral intracranial guide cannulae (22 gauge, $9 \mathrm{~mm}$; Plastics One) stereotaxically aimed $1 \mathrm{~mm}$ above the CeA or BNST using the following coordinates relative to bregma: for the $\mathrm{CeA}, \mathrm{AP}-2.4, \mathrm{ML} \pm 4.0$, and $\mathrm{DV}-6.4$ from skull surface; and for the BNST, AP $-0.6, \mathrm{ML} \pm 3.5$, and DV -6.2 from skull surface with a lateral inclination of $15^{\circ}$ (Paxinos and Watson, 2005). For cannula placement within the BNST, care was taken to target the ventral portion of the BNST because this is the area with the highest noradrenergic innervation (Kilts and Anderson, 1986) compared with the dorsal BNST, which receives little norepinephrine input (Phelix et al., 1992). Cannulae were secured with dental cement and four stainless steel screws that anchored the assembly to the skull. An obdurator was placed inside each guide cannula to seal the opening and thus maintain patency and reduce the risk of infection. Immediately after surgery, subjects each received a subcutaneous injection of the nonopiate analgesic flunixin meglumine (FluMeglumine, $1.3 \mathrm{mg} / \mathrm{kg}$; Phoenix Pharmaceuticals) and 3 $\mathrm{ml}$ of $0.9 \%$ physiological saline to prevent dehydration. In addition, animals received the antibiotic ticarcillin disodium/clavulanate potassium (Timetin; $50 \mathrm{mg}$ in $0.25 \mathrm{ml}$, i.v.) and $0.1 \mathrm{ml}$ of heparin $(6.0 \mathrm{IU} / 0.1$ $\mathrm{ml}$ prepared in $0.9 \%$ physiological saline, i.v.) to promote catheter patency and to reduce the risk of microbial infection. After surgery, catheter patency was maintained through daily flushing with $0.1 \mathrm{ml}$ of Timetin antibiotic $(10 \mathrm{mg}$ in $0.1 \mathrm{ml}$, i.v.), followed by $0.1 \mathrm{ml}$ of heparinized $0.9 \%$ physiological saline. Animals were allowed to recover for $7 \mathrm{~d}$ before behavioral testing and were handled daily during their recovery. Catheter patency was established weekly through assessing the loss of the righting reflex after intravenous injection of the fast-acting barbiturate methohexital (Brevital, $2.0 \mathrm{mg} / \mathrm{kg} / 0.1 \mathrm{ml}$ ). Animals that were unresponsive to Brevital before testing were reimplanted with a new catheter using the left jugular vein and given additional days for recovery. If catheter patency failed during the course of behavioral testing, that animal was removed from data analysis; a total of five animals were removed due to catheter failure.

Drugs. Cocaine hydrochloride (provided by the National Institute on Drug Abuse) was dissolved in 0.9\% physiological saline and sterile filtered. Cocaine was diluted to a dose of $1 \mathrm{mg} / \mathrm{kg}$ and delivered in a volume of $0.1 \mathrm{ml}$ over a period of $4.3 \mathrm{~s}$ via a $10 \mathrm{ml}$ syringe nested in a motorized syringe pump (Razel Scientific Instruments). The dose of $1 \mathrm{mg} / \mathrm{kg}$ intravenous cocaine was chosen based upon its ability to consistently produce optimal runway behavior and consistent CPPs and CPAs (Raven et al., 2000; Guzman and Ettenberg, 2004; Ettenberg and Bernardi, 2006; Su et al., 2013). NE receptor antagonists consisted of an equal mixture of either 0.5 or $1.0 \mathrm{nmol}$ each of the $\beta 1$ and $\beta 2$ antagonists betaxolol and ICI 118551 (Tocris Bioscience) dissolved in sterile water. All subjects received only one dose of antagonist or vehicle administered in a volume of $0.5 \mu \mathrm{l} /$ side over $90 \mathrm{~s}$ via a $10 \mu \mathrm{l}$ Hamilton syringe seated in a motorized syringe pump (Razel Scientific Instruments). Doses of NE antagonists were chosen based upon their ability to attenuate stress-induced reinstatement of cocaine seeking when delivered into the CeA or BNST (Leri et al., 2002) and to block opiate-withdrawal-induced CPAs when delivered into the BNST (Aston-Jones et al., 1999).

Runway self-administration. Eighty animals were assigned to the runway experiment, which used two identical wooden straight-arm runways as the test apparatus. Each measured $155 \mathrm{~cm} \mathrm{~L} \times 15 \mathrm{~cm} \mathrm{~W} \times 40 \mathrm{~cm} \mathrm{H}$. On opposite ends of the straight alley were an identically sized start box and goal box (each measuring $24 \mathrm{~cm} \times 25 \mathrm{~cm} \times 40 \mathrm{~cm}$ ) both separated from the runway by a retractable door. Along the interior length of the alley were 13 infrared photodetector-emitter pairs positioned in the walls $\sim 16$ $\mathrm{cm}$ apart from one another. Input from these photocells was fed through a custom Any-Maze (AMi) interface (Stoetling) to a desktop computer that recorded the subjects' location in the runway in real time throughout each trial. In addition, above each runway were two magnetic rails that ran in parallel $0.75 \mathrm{~cm}$ apart down the entire length of the runway. Seated between the rails was a flow-through plastic swivel (375-22PS; Instech Laboratories) that connected the animal's intravenous catheter to a syringe in the drug delivery pump via plastic tubing (PE20). The swivel had a Plexiglas collar that prevented it from falling through between the magnetic rails. Attached to the underside of the collar was a pot magnet the polarity of which was aligned opposite to that of the rails, thereby causing the swivel to float between and slightly above the rails. This provided the animal with minimum resistance as it traversed through the alley pulling the drug line and swivel above and behind it. For a more detailed description of the runway apparatus, see Geist and Ettenberg (1990).

One day before the initiation of runway testing, subjects were acclimated to the apparatus by placing them individually into the start box and permitting them to wander freely for $10 \mathrm{~min}$ (the goal door remained closed to prevent entry into the goal box). After acclimation, 15 single daily runway trials were conducted. Ten minutes before each trial, subjects were individually removed from their home cages, internal infusion cannulae (28 gauge, $10 \mathrm{~mm}$ long; Plastics One) were inserted into their intracranial guide cannulae, and slow bilateral infusions $(0.5 \mu \mathrm{l} / \mathrm{side})$ of one of two doses of the NE antagonists betaxolol and ICI 118551 (0.5 or $1 \mathrm{nmol}$ each) or vehicle was applied directly into the CeA or BNST. After each infusion, a $1 \mathrm{~min}$ period was allowed for the solutions to diffuse away from the cannula tips, infusion cannulae were removed, obdurators were replaced, animals were returned to their home cages for $10 \mathrm{~min}$, and then a single runway trial was conducted.

Each subject was attached to the drug delivery system by inserting an internal cannula into the guide cannula affixed to the animal's back; the internal cannula was connected via PE20 tubing to the syringe containing the cocaine solution (as described in the first paragraph of this section). Subjects were then placed into the start box of one of the two runways and, after $5 \mathrm{~s}$, the start door was opened and the trial thereby initiated. All trials for a given subject were conducted in the same runway. Animals were free to traverse the runway until they entered the goal box, at which point the goal door was closed behind them and an infusion of $1 \mathrm{mg} / \mathrm{kg} /$ $0.1 \mathrm{ml}$ cocaine was administered. Subjects remained in the goal box for 5 min after the infusion and were then disconnected from the drug delivery system and returned to their home cage. All animals were given single daily runway trials over 15 consecutive days. This experiment yielded six groups of animals: rats running for intravenous cocaine after intra-CeA administration of either $1 \mathrm{nmol}$ each of betaxolol + ICI 118551 (CeA High Dose, $n=9$ ), $0.5 \mathrm{nmol}$ each of betaxolol + ICI 118551 (CeA Low Dose, $n=7)$, or vehicle $(n=11)$; and rats running for intravenous cocaine after intra-BNST administration of $1 \mathrm{nmol}$ each betaxolol + 
ICI 118551 (BNST High Dose, $n=7$ ), $0.5 \mathrm{nmol}$ each betaxolol + ICI 118551 (BNST Low Dose, $n=9$ ), or vehicle $(n=9)$.

To determine anatomical specificity of NE antagonist effects on runway behavior, two additional groups of intravenous catheterized animals were implanted with bilateral intracranial cannula aimed dorsal to and distinct from the CeA $(n=7)$ or BNST $(n=7)$. After surgery, these "anatomical control" animals underwent runway testing identical to that described above with each trial preceded by an intracranial infusion of a dose of the NE antagonists (either $1 \mathrm{nmol}$ or $0.5 \mathrm{nmol} / \mathrm{side}$ ) that were found to have significant effects on runway behavior when infused into the target CeA or BNST regions.

Three dependent measures were recorded on every trial. "Start latency" was defined as the time required for the animal to leave the start box (i.e., time to break the first infrared photodetector-emitter in the alley) once the start door was opened. "Run time" was defined as the amount of time required for the rat to enter the goal box after it had left the start box. "Retreats" were counted as the number of times an animal halted its forward motion and retreated back at least the length of two photodetector-emitters in the runway $(\sim 30 \mathrm{~cm})$.

In traditional self-administration studies, animals that do not learn to lever press for the drug reinforcer are simply removed from the study. With the runway protocol, this screening is accomplished by examining the change in start latencies over trials. When the goal box contains positive (including mixed positive and negative) stimuli, start latencies decrease as trials progress (Ettenberg, 2009). In the present study, as in our previous work (Wenzel et al., 2011), those animals that had an average start latency over the final three trials that was not shorter (reflecting faster responding) than their average over the initial three trials were removed from the study on the basis that learning to associate the goal box with the reinforcing drug could not be verified. Based upon this criterion, 11 rats were removed from the runway study.

Spontaneous locomotor activity test. To ensure that the centrally applied NE treatments did not produce nonspecific alterations in the response capacity of the subjects, a subset of animals from the runway experiment were examined in a test of spontaneous locomotor activity. Locomotor behavior was measured in 12 identical Plexiglas chambers each measuring $20 \mathrm{~cm} \mathrm{~L} \times 40 \mathrm{~cm} \mathrm{~W} \times 20 \mathrm{~cm} \mathrm{H}$ (Kinder Scientific). Chambers were lined with 15 infrared photodetector-emitter pairs evenly spaced along their long axis and 7 along their narrow axis, each located $8 \mathrm{~cm}$ from the floor of the chamber. Movement within the chamber produced photobeam interruptions that were recorded by a desktop computer running custom software (Kinder Scientific).

At the start of testing, all animals were allowed to acclimate to the locomotor chambers for $60 \mathrm{~min}$. Rats were then removed from their testing chambers and received bilateral microinjections of either the high dose of $\mathrm{NE}$ antagonists used in runway testing $(1 \mathrm{nmol} / 0.5 \mu \mathrm{l} /$ per side betaxolol + ICI 118551) or vehicle into either the CeA or BNST. After intracranial injections, animals were returned to their home cages for 10 min before placement back into the locomotor test chambers for a single 15 min test session. The data therefore reflect locomotor activity for 4 groups of animals: rats that received pretreatment with vehicle in the CeA $(n=6)$, rats that received the high dose of NE antagonists in the CeA $(n=6)$, rats that were pretreated with vehicle delivered to the BNST ( $n=$ 5 ), and rats that received the high dose of NE antagonists delivered to the $\operatorname{BNST}(n=6)$.

Conditioned place test. Two identical rectangular wooden conditioned place test boxes served as the apparatus. Each box $(156 \mathrm{~cm}$ long $\times 34 \mathrm{~cm}$ wide $\times 30 \mathrm{~cm}$ high) was subdivided into three separate compartments separated by removable walls: two equally sized large chambers $(61 \mathrm{~cm} \times$ $30 \mathrm{~cm}$ ) at opposite ends separated by a smaller intermediate chamber ( 34 $\mathrm{cm} \times 30 \mathrm{~cm})$. One of the two larger compartments was painted black with Plexiglas flooring and had an acetic acid scent (10\% solution) swabbed $5 \mathrm{~cm}$ from the top of the compartment to serve as an olfactory cue. The other large chamber was painted white, had a soft gray bedding covering the floor (Carefresh; Absorption Corporation), and no additional olfactory cues. The smaller intermediate chamber was painted gray with wood flooring. Each compartment, therefore, had unique visual, tactile, and olfactory properties and yielded no reliable inherent preferences before conditioning. Situated above each apparatus was a digital camera that detected and recorded the precise location of each animal in real time via a desktop computer running Any-Maze software (Stoetling).

Place conditioning consisted of three phases performed over 10 consecutive days in a new group of experimentally naive subjects: a baseline trial, eight place conditioning trials, and a final preference test. For baseline, the interior walls separating each compartment were removed, subjects were placed into the middle gray section of the apparatus, and the time spent in each of the three compartments was recorded over $15 \mathrm{~min}$. The following day, the dividing walls were placed back into the apparatus and place conditioning began. Before each of the eight conditioning trials, rats received an intracranial injection of either the high dose of the two NE antagonists or vehicle delivered into either the CeA or BNST, as described in Drugs, above. Ten minutes later, each subject was administered an intravenous injection of either saline/vehicle or cocaine (1.0 $\mathrm{mg} / \mathrm{kg} / 0.1 \mathrm{ml}$ over $4.3 \mathrm{~s}$ ) and placed into either the white or black compartment for $5 \mathrm{~min}$. On the following day, each rat received the alternate treatment (cocaine or saline) and was placed in the alternate colored environment. Therefore, at the conclusion of conditioning, each subject had experienced four parings of cocaine with one side of the apparatus and four pairings of saline with the alternate side-each in the presence of NE antagonist challenge. On each conditioning trial, some animals were placed into the conditioning chamber immediately after cocaine injection (the "Immediate" groups) and the remainder 15 min afater injection (the "Delayed" groups). To ensure an unbiased design (Carr et al., 1989), the order of intravenous injection (receiving either vehicle or cocaine on the first conditioning trial) and the drug-paired compartment (either black or white) were counterbalanced within each group. This study thus yielded eight groups of animals: rats that received intra-CeA $\mathrm{NE}$ antagonist pretreatment and then underwent place conditioning for the immediate $(n=7)$ or delayed $(n=7)$ effects of intravenous cocaine; rats that were pretreated with intra-CeA vehicle and underwent place conditioning for either the immediate $(n=8)$ or delayed $(n=8)$ effects of cocaine; rats that received intra-BNST NE antagonist pretreatment and then underwent place conditioning for the immediate $(n=6)$ or delayed $(n=14)$ effects of intravenous cocaine; and rats that were pretreated with intra-BNST vehicle and underwent place conditioning for either the immediate $(n=7)$ or delayed $(n=15)$ effects of cocaine.

Learned preferences or aversion are by definition a shift in the time spent in a drug-paired environment as a result of experiencing that environment in the presence of the drug. Therefore, we operationally define CPPs and CPAs as reliable shifts in the time spent in the drug-paired environment on test day relative to baseline (Ettenberg et al., 1999; Knackstedt et al., 2002; Ettenberg and Bernardi, 2007). This analysis requires a calculation of "differences scores"; that is, the average time rats spent in the cocaine-paired compartment on test day minus the time spent in that environment on the preconditioning baseline trial. Therefore, a score of " 0 " reflects no change in preference as a result of drugplace conditioning, whereas positive scores indicate that animals spent more time in the drug-paired environment after conditioning (demonstrating a learned preference for the drug-paired environment, i.e., a $\mathrm{CPP}$ ) and negative scores indicate an avoidance of the drug-paired side after conditioning (i.e., a CPA).

Histology. After completion of behavioral testing, animals were killed with a lethal dose of sodium pentobarbital and phenytoin sodium solution (Euthasol; Virbac). Brains were removed and stored in $10 \%$ formalin, sliced on a cryostat (CM 1800; Leica) into $40 \mu \mathrm{m}$ frozen sections, and then mounted on $1.5 \%$ gelatin-coated slides and stored at $-20^{\circ} \mathrm{C}$ before staining. Slides were stained in a $1.0 \%$ cresyl violet solution and viewed under magnification to determine cannula placement within the CeA or ventral BNST. A subject's inclusion in this experiment required strict histological confirmation of bilateral placements directly above the targeted brain areas under investigation. This inherently necessitated the removal of any subjects from the study with cannulae that were not both appropriately situated in brain and any animals exhibiting damage (necrosis) around the injection site; this decision was made by an individual (A.E.) blind to the group assignment of the animal. A total of 41 animals (of the original 180) were removed from the runway and place conditioning tests because they did not meet this criterion. The group sample 

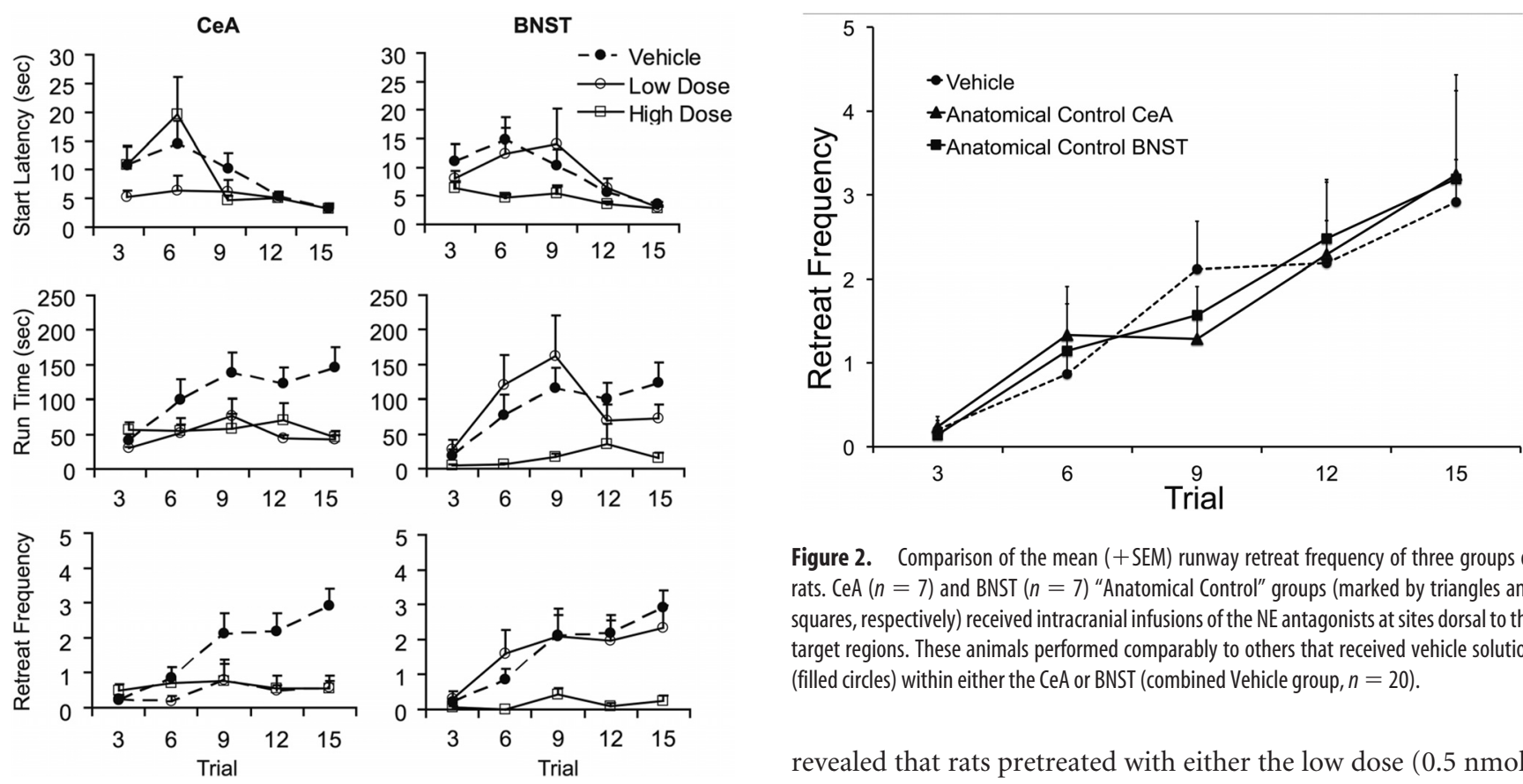

Figure 1. Group mean (+SEM) start latencies (top), run times (middle), and retreat frequencies (bottom) of rats running an alley for a single daily intravenous injection of $1.0 \mathrm{mg} / \mathrm{kg} /$ $0.1 \mathrm{ml}$ cocaine over 15 trials. Scores have been averaged across $3 \mathrm{~d}$ bins. Each runway trial was preceded by bilateral intracranial infusion of either the "Low Dose" $(0.5 \mathrm{nmol} / 0.5 \mu \mathrm{l} / \mathrm{side})$ or the "High Dose" (1.0 nmol/0.5 $\mu \mathrm{l} /$ side) of the NE $\beta$-antagonists (betaxolol + ICI 118551) or "Vehicle" delivered directly into either the CeA or BNST. This figure thus illustrates the data from 5 groups of animals: CeA High Dose $(n=9)$, CeA Low Dose $(n=7)$, BNST High Dose $(n=7)$, BNST Low Dose $(n=9)$, and the combined Vehicle group $(n=20)$.

sizes described in the sections above reflect the actual number of animals that completed the study and were included in the data analyses.

\section{Results}

\section{Runway self-administration analysis}

Figure 1 illustrates the mean ( + SEM) performance for all groups over the 15 runway trials. Note that the data were averaged over three trial bins to increase the clarity of the results by reducing some of the inherent trial-to-trial variability common in the use of one-trial per day test protocols. Separate two-factor (Group $\times$ Trial) ANOVAs (with repeated measures on trial) were used to evaluate group performance on each of the three dependent measures as depicted in Figure 1. Because no group differences were found in the performance on any of the dependent measures of animals administered vehicle into the CeA versus the BNST, the two groups were combined into a single "vehicle" control group for all statistical analyses.

The Group $\times$ Trial ANOVA computed on the start latency data (Fig. 1, top) yielded a significant main effect of Trial $\left(F_{(4,188)}=7.02\right.$, $p<0.001)$, but no main effect of Group $(p>0.05)$ nor a Group $\times$ Trial interaction $(p>0.05)$. Therefore, when averaged across all animals, start times reliably decreased over trials. In contrast, the ANOVA computed on run times (Fig. 1, middle) identified significant main effects of Trial $\left(F_{(4,188)}=4.82, p=\right.$ $0.001)$ and Group $\left(F_{(4,47)}=2.63, p=0.046\right)$, as well as a significant Trial $\times$ Group interaction $\left(F_{(16,188)}=1.90, p=0.027\right)$. Therefore, although, on average, all animals took longer to enter the goal box as trials progressed, groups performed differently from one another in terms of both average run times across the entire experiment and the pattern of behavior exhibited over trials. Fisher's post hoc least significant difference (LSD) analyses

Figure 2. Comparison of the mean ( + SEM) runway retreat frequency of three groups of rats. CeA $(n=7)$ and BNST ( $n=7)$ "Anatomical Control" groups (marked by triangles and squares, respectively) received intracranial infusions of the NE antagonists at sites dorsal to the target regions. These animals performed comparably to others that received vehicle solution (filled circles) within either the CeA or BNST (combined Vehicle group, $n=20$ ).

revealed that rats pretreated with either the low dose $(0.5 \mathrm{nmol} /$ $0.5 \mu \mathrm{l} /$ side) of the NE antagonists into the CeA or the high dose ( $1 \mathrm{nmol} / 0.5 \mu \mathrm{l} / \mathrm{side}$ ) into the BNST ran more quickly (i.e., had shorter run times) than vehicle controls ( $p=0.05$ and $p=0.024$, respectively). The high dose of intra-CeA antagonists also reduced run times, but within-group variability rendered that effect only marginally significant $(p=0.066)$.

The ANOVA computed on the mean approach-avoidance retreat frequency data (Fig. 1, bottom) similarly identified statistically significant main effects for Trial $\left(F_{(4,188)}=7.63, p<0.001\right)$ and Group $\left(F_{(4,47)}=3.40, p=0.016\right)$, as well as a significant Group $\times$ Trial interaction $\left(F_{(16,188)}=2.58, p=0.001\right)$. Therefore, when averaged across all animals, retreat frequencies increased over trials. However, the magnitude of this effect and its pattern of performance over trials varied as a function of the pretreatment condition of the subjects. Post hoc LSD analyses demonstrated that although vehicle rats developed the typical retreat behavior, pretreatment with either dose of the NE antagonists into the CeA (CeA Low Dose, $p=0.029$; CeA High Dose, $p=0.038$ ) or the high dose of NE antagonist into the BNST ( $p=$ $0.007)$ prevented the development of retreats. The significant interaction obtained in the ANOVA therefore stemmed from the fact that although retreat frequencies were comparable across all groups during early trials, by the end of testing, the groups behaved differently from each other (Fig 1, bottom).

Two additional groups of animals served as anatomical controls in which intracranial infusion sites were located dorsal to the CeA or BNST. Given that only the highest dose of NE antagonists ( $1 \mathrm{nmol}$ each betaxolol and ICI 118551 in $0.5 \mu \mathrm{l} /$ side) blocked the development of retreat behavior when delivered into the BNST, all BNST anatomical controls received this dose $(n=7)$. However, both the high dose $(1 \mathrm{nmol})$ and the low dose $(0.5 \mathrm{nmol}$ each betaxolol and ICI 118551 in $0.5 \mu \mathrm{l} /$ side) were effective at blocking retreats when delivered into the $\mathrm{CeA}$; therefore, half the CeA anatomical controls were pretreated with the high dose of antagonists $(n=3)$ and the remainder with the low dose $(n=4)$ (Fig. 2). Three separate two-way (Group $\times$ Trial) ANOVAs were used to compare the two anatomical control groups with the vehicle control group described in Runway self-administration, above. These analyses confirmed main effects of Trial across all three behavioral measures: that is, all animals exhibited de- 


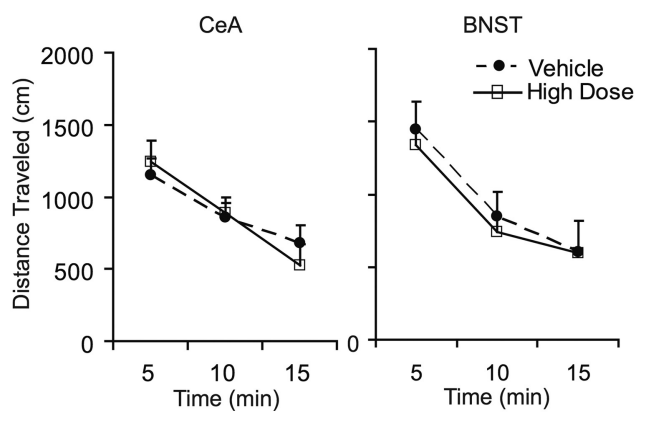

Figure 3. Mean (+SEM) distance traveled $(\mathrm{cm})$ of animals during a 15 min locomotor activity test conducted under the influence of intracranial infused Vehicle into the CeA $(n=6)$ or the BNST $(n=5)$ or the High Dose $(1.0 \mathrm{nmol})$ of each of the 2 NE $\beta$-antagonists delivered bilaterally $(0.5 \mu \mathrm{l} / \mathrm{side})$ into the CeA $(n=6)$ or BNST $(n=6)$. ANOVA confirmed that intracranial $\mathrm{NE}$ antagonist treatment had no reliable impact on spontaneous locomotor activity.

creases in start times over trials $\left(F_{(4,124)}=6.76, p<0.001\right)$, slower run times over trials $\left(F_{(4,124)}=5.19, p=0.001\right)$, and increased retreat frequency over trials $\left(F_{(4,124)}=16.68, p<0.001\right)$. By way of example, Figure 4 depicts the retreat frequency of the vehicle and anatomical control groups over the course of runway testing. Of particular relevance to the present study was the fact that the ANOVAs revealed no main effects for Group $(p>0.05)$ for any of the three dependent measures. Therefore, the behavioral changes produced by intra-NE receptor antagonism depicted in Figure 4 were not observed in animals with cannula placements outside of the CeA or BNST.

\section{Spontaneous locomotor activity}

To ensure that changes in runway behavior were not the result of nonspecific motoric effects of the NE antagonist treatment, a subset of animals from the runway experiment underwent testing of spontaneous locomotor activity after intracranial administration of the highest dose of antagonist or vehicle. At the start of testing, each rat was placed inside a locomotor chamber and allowed to habituate to the apparatus for $60 \mathrm{~min}$ (data not shown). ANOVA confirmed that there were no reliable differences in baseline locomotor activity among animals before intracranial antagonist infusion. After habituation, each animal was infused with either the "High Dose" of NE antagonists ( $1 \mathrm{nmol} / 0.5 \mu \mathrm{l} /$ side betaxolol + ICI 118551) or vehicle delivered into either the CeA or BNST and then, 10 min later, was returned to its assigned locomotor chamber for $15 \mathrm{~min}$. Figure 3 illustrates mean ( \pm SEM) activity levels (measured as distance traveled) over the 15 min locomotor test session. A three-way (Time $\times$ Brain Region $\times$ Pretreatment) ANOVA confirmed what appears to be obvious from the figure: that all animals decreased their locomotor output over the duration of the $15 \mathrm{~min}$ test period (main effect of Time, $F_{(2,38)}=$ $60.6, p<0.001)$. However, there were no significant interactions and no main effects of either Brain Region or Pretreatment ( $p>0.05)$. $\mathrm{NE}$ antagonist treatment did not disrupt spontaneous locomotor output relative to vehicle controls.

\section{Conditioned place test analysis}

Before place conditioning, a single two-tailed within-group $t$ test confirmed that rats exhibited no significant inherent preferences for the drug-paired versus saline-paired environment before conditioning; that is, during baseline $\left(t_{(72)}=1.40, p>0.05\right)$. The results of drug-place conditioning are depicted in Figure 4, which shows the mean ( \pm SEM) Difference Scores (Test-Baseline) for CeA (Fig. 4, left) and BNST (Fig. 4, right) animals. As described in

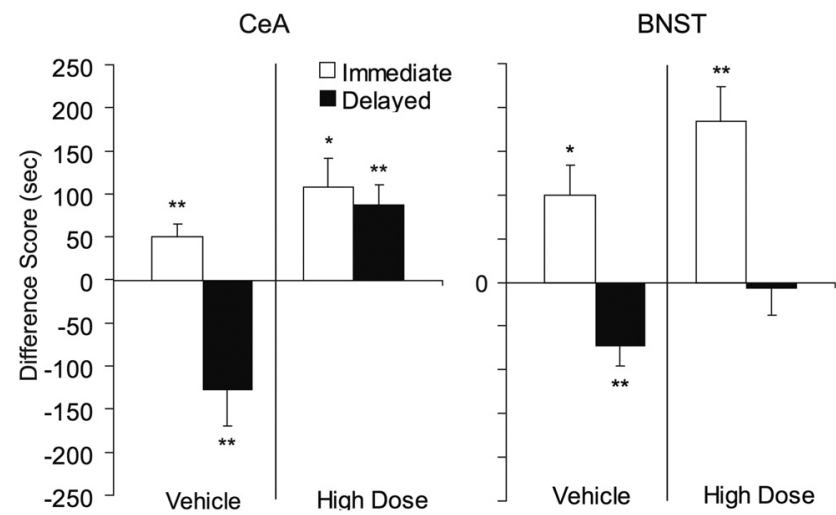

Figure 4. Mean (+SEM) difference scores (test day minus baseline) for animals conditioned to associate a unique environment with either the immediate/positive effects of intravenous cocaine (unfilled/white bars) or the delayed/negative effects of the drug present $15 \mathrm{~min}$ after injection (black/filled bars). Scores $>0$ reflect that subjects spent more time in the drug-paired environment on test day relative to baseline, scores $<0$ reflect aversion for the drug-paired side, and a score of 0 reflects no change in place preference on the test day relative to initial baseline. Before each conditioning trial, each rat was pretreated with either "Vehicle" or the "High Dose" of the $2 \mathrm{NE} \beta$-receptor antagonists ( $1.0 \mathrm{nmol} / 0.5 \mu \mathrm{l} /$ side betaxolol $+\mathrm{ICl} 118551$ ) delivered directly into either the CeA or BNST. This study thus yielded 8 groups of animals: rats that received intra-CeA NE antagonist pretreatment and then underwent place conditioning for the immediate $(n=7)$ or delayed ( $n=7$ ) effects of intravenous cocaine; rats that were pretreated with intra-CeA vehicle and underwent place conditioning for either the immediate $(n=8)$ or delayed $(n=8)$ effects of cocaine; rats that received intra-BNST NE antagonist pretreatment and then underwent place conditioning for the immediate $(n=6)$ or delayed ( $n=14$ ) effects of intravenous cocaine; and rats that were pretreated with intra-BNST vehicle and underwent place conditioning for either the immediate $(n=7)$ or delayed ( $n=15$ ) effects of cocaine. One-sample $t$ tests identified which groups (designated by asterisks) exhibited a statistically reliable shift from 0 (i.e., a CPP or (PA). ${ }^{*} p \leq 0.05 ;{ }^{* *} p \leq 0.01$.

Conditioned place test, Materials and Methods, above, difference scores reflect the mean shift from baseline either toward (preference) or away from (aversion) the cocaine-paired side so that positive scores reflect increases in preference for the drug-paired side after conditioning, whereas negative scores reflect avoidance of the drug-paired side on the test day relative to baseline. A three-factor (Conditioning $\times$ Pretreatment $\times$ Brain Region) ANOVA computed on the data depicted in Figure 4 revealed main effects of Conditioning (immediate vs delayed cocaine; $F_{(1,64)}=38.26, p<0.001$ ) and of Pretreatment (vehicle vs NE antagonist treatment; $F_{(1,64)}=21.47, p<0.001$ ), but no significant difference between CeA and BNST and no significant interactions $(p>0.05)$. Because a CPP or CPA is defined here as a statistically significant shift in preference on test day compared with baseline, the magnitude of each group's difference score was evaluated using individual $t$ tests that compared each group's mean difference score to a value of " 0 ." Given our a priori hypothesis that vehicle-pretreated subjects would develop the characteristic pattern of place preferences and aversions that we have previously reported (for review, see Ettenberg, 2004), directional one-tailed single sample $t$ tests were computed for each control group. In contrast, because the effects of the NE antagonists on CPP/CPA were unknown before the present study, two-tailed independent sample $t$ tests were used for all antagonistpretreated groups. The two vehicle pretreated "Immediate" groups exhibited statistically significant shifts toward the cocaine-paired environment on test day relative to baseline (i.e., their difference score was reliably $>0$; CeA $t_{(7)}=3.46, p<0.01$; BNST $\left.t_{(6)}=2.92, p<0.05\right)$, whereas vehicle pretreated "Delayed" group animals spent less time in the cocaine-paired side on test day after conditioning $\left(\mathrm{CeA} t_{(7)}=-3.03, p<0.01\right.$; BNST 


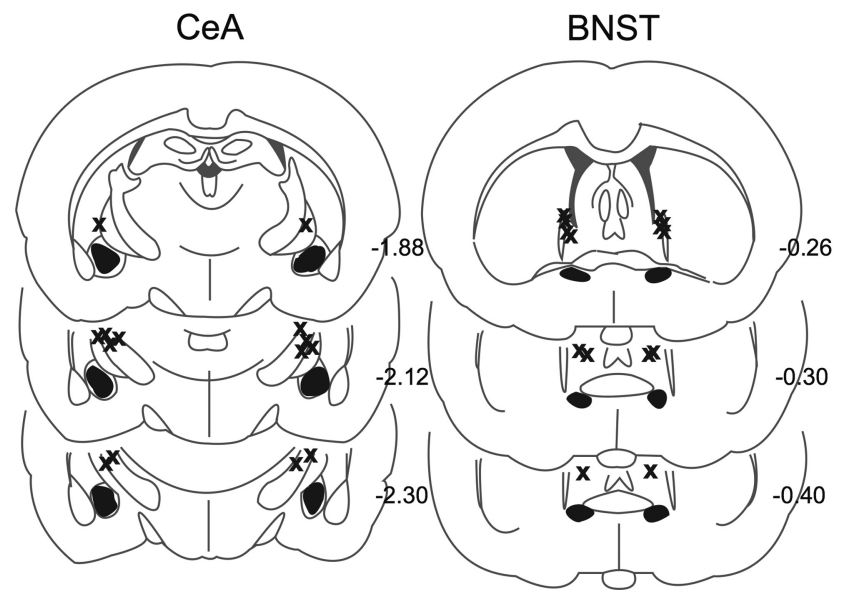

Figure 5. Histological confirmation of cannula placements for subjects in the CeA (left) or BNST (right) group. Shaded areas indicate the regions within which successful cannula placements were identified. " $x$ " indicates the cannula location of rats assigned to the anatomical control groups (see text for more information). The numbers to the right and below each coronal section identify distance from bregma $(\mathrm{mm})$. The sections were adapted from Paxinos and Watson (2005).

$\left.t_{(14)}=-3.27 ; p<0.01\right)$. Therefore, vehicle animals developed CPPs for an environment paired with the immediate effects of cocaine and CPAs for an environment paired with the delayed effects of the drug. Pretreatment with the "High Dose" of NE antagonists delivered into either the CeA or BNST did not disrupt the development of CPPs produced by the immediate effects of intravenous cocaine $\left(\mathrm{CeA} t_{(6)}=3.18, p<0.05\right.$; $\mathrm{BNST} t_{(5)}=4.65$, $p<0.01]$. However, NE antagonist pretreatment into either the CeA or BNST prevented the development of CPAs for the delayed effects of cocaine. In fact, $\mathrm{NE}$ antagonists delivered to the CeA resulted in a preference, instead of an aversion, for the environment paired with cocaine's delayed effects $\left(t_{(6)}=3.92, p<0.01\right)$, whereas NE antagonism within the BNST simply blocked the development of CPAs $(p>0.05)$.

\section{Histology}

Figure 5 depicts the regions within which the cannula placements were located for both the CeA and BNST. As indicated in Histology, above, animals for which bilateral cannula tracks could not be confirmed as located immediately above their intended brain target were removed from the data analyses. An " $x$ " in the figure denotes the cannula placements of the 14 animals used as "anatomical controls."

\section{Discussion}

In addition to its well documented rewarding effects, cocaine administration has been shown to produce a delayed aversive state in both humans and animals (see Introduction for references). The present study sought to explore the role of NE neurotransmission within two structures of the extended amygdala (the CeA and BNST) in modulating cocaine's aversive/anxiogenic effects. To this end, the impact of NE $\beta$-receptor antagonism within either region was examined in two behavioral assays: an operant self-administration runway and a modified conditioned place test. Runway results confirmed those that we reported previously showing that rats traversing a straight alley for intravenous cocaine develop over trials, a pattern of approachavoidance "retreat" behavior about goal-box entry stemming from the drug's dual and opposing actions (Ettenberg and Geist, 1991, 1993; Ettenberg, 2004). Pretreating animals with intra-CeA or intra-BNST infusions of a mixture of $\beta 1+\beta 2$ receptor antagonists (betaxolol and ICI 118551) significantly reduced run times and retreat frequency, suggesting that NE neurotransmission within these two brain structures is contributing to the anxiogenic response to cocaine. Importantly, similar reductions in retreat behavior were not seen in anatomical controls receiving NE antagonist pretreatment into sites dorsal to the CeA or BNST.

This conclusion is consistent with a number of findings in the literature. For example, the CeA and BNST have been implicated in the behavioral response of animals to stressful and anxiogenic stimuli (Schweimer et al., 2005; Davis, 2006), in the negative affective state resulting from drug withdrawal (Gracy et al., 2001; Hamlin et al., 2004; Nakagawa et al., 2005), and in stress-induced reinstatement of drug-seeking behavior (Shaham et al., 2003). Further, both the CeA and BNST receive noradrenergic innervation from the ventral noradrenergic bundle (Moore and Bloom, 1979), which has long been implicated in the response of animals to aversive stimuli (Itoi and Sugimoto, 2010), and the presentation of acute stress-inducing stimuli results in increased NE neurotransmission within these two regions (Pacak et al., 1995; Galvez et al., 1996). The role of NE in cocaine-induced anxiety has also been suggested. Schank et al. (2008) reported that dopamine $\beta$ hydroxylase (DBH) knock-out mice or wild-types pretreated with the $\mathrm{DBH}$ inhibitor disulfiram or the $\beta$-receptor antagonist propranolol were resistant to the anxiogenic effects of acute cocaine. Further, systemic administration of betaxolol has been shown to ameliorate withdrawal-induced anxiety behavior after chronic cocaine administration (Rudoy, and Van Bockstaele, 2007; Rudoy et al., 2009). In addition, intra-BNST infusion of the NE receptor antagonist drugs and doses used here (betaxolol and ICI 118551) have been shown to attenuate opiate withdrawal-induced CPAs (Aston-Jones et al., 1999) and both intra-CeA and intra-BNST administration blocked foot-shockinduced reinstatement of cocaine seeking (Leri et al., 2002). We therefore hypothesize that our observed reduction in retreat behavior stems from an attenuation of the anxiogenic response to cocaine resulting from a disruption of NE neurotransmission within the CeA and BNST.

As described in the Introduction, retreat behaviors stem from the animal's concurrent association of the goal box with both the positive/rewarding and negative/anxiogenic properties of the stimulus delivered there (Miller, 1944; Ettenberg, 2004). Indeed, the same retreat behavior is observed in animals running to a goal box associated with known positive and negative stimuli (e.g., food + foot shock; Miller, 1944; Geist and Ettenberg, 1997; Cohen et al., 2009). However, this necessarily implies that experimental treatments that reduce retreats (i.e., that attenuate the conflict behavior) might do so by decreasing the magnitude of the aversive quality of the goal box experience, increasing the magnitude of the positive experience, or both. The fact that start latencies tended to decrease over trials for all groups suggests that the "approach" component of runway behavior was left relatively intact. This suggests that the changes in retreat behavior were attributable to reductions in the aversive impact of the cocaine, a conclusion bolstered by the results of the conditioned place test.

Vehicle-pretreated rats developed CPPs for the immediate/ positive effects of cocaine and CPAs for the delayed/negative effects of the drug, again confirming our previous reports (Ettenberg et al., 1999; Knackstedt et al., 2002; Ettenberg and Bernardi, 2007). However, $\beta$-receptor antagonism within either the CeA or BNST reliably prevented the establishment of CPAs to the environments associated with the delayed/anxiogenic effects of cocaine while leaving the immediate positive effects of the drug 
(as measured by CPPs) unaltered. In fact, animals pretreated with $\mathrm{NE}$ antagonists into the CeA developed preferences for the side paired with cocaine's delayed effects. The CPP data appear to indicate that $\mathrm{NE}$ antagonism within this region may not only eliminate the negative impact of cocaine, but may also prolong the duration of cocaine's positive effects, likely through the removal of the competing delayed/negative state. This effect was not observed in NE-pretreated BNST animals, suggesting that NE antagonism produces functionally discernable differences within these two regions of the extended amygdala. Our previous data have illustrated functional differences between the CeA and BNST in that lidocaine inactivation of the BNST completely blocked the development of retreat behaviors in the runway, whereas CeA lidocaine inactivation only delayed retreat development (Wenzel et al., 2011).

As referenced earlier in the Discussion the present findings fit well with prior studies on the role of NE neurotransmission within the extended amygdala in stress and anxiety. However, the noradrenergic system is also known to be involved in psychomotor function (Aston-Jones et al., 1991; Gil et al., 1992) and peripheral administration of $\beta$-receptor antagonists has been shown to reduce locomotor activity (Stone et al., 1995). To rule out any nonspecific locomotor effects arising from the intracranial treatment used here, animals underwent locomotor activity testing after infusion of the high dose of NE antagonist into either the CeA or BNST. Results confirmed that antagonist treatment into either region had no effect on spontaneous locomotion. Therefore, the observed reductions in retreat behavior did not stem from NE-antagonist-mediated disruption of the animals' motoric capacity. Aside from its locomotor effects, NE receptor antagonism has been shown to interfere with the establishment of both emotional and drug-associated memories (van Stegeren, 2008; Otis and Mueller, 2011). Therefore, one might argue that the reductions in retreats and the reversal of cocaine-induced CPAs in NE-antagonist-treated animals stem from deficits in the subjects' capacity to recall the affective state associated with cocaine. This hypothesis, although plausible, remains unlikely in the present context. First, in the runway, all groups exhibited shorter start latencies over trials demonstrating that the motivation to seek the drug based on past experiences in the runway remained intact and in fact increased as testing progressed. Second, a memory-deficit hypothesis does not account for why only the CPAs were attenuated by the NE antagonist treatment and not the CPPs. Of course, it is possible that the NE antagonists selectively interfered with the subjects' ability to form place associations with the negative and not the positive properties of cocaine. However, we believe that a more parsimonious explanation is that NE $\beta$-receptor antagonism within the CEA and BNST is integral to the experience of the anxiogenic effects of cocaine.

The present findings suggest that the same neural mechanisms responsible for the dysphoria reported during withdrawal from chronic drug exposure (Gracy et al., 2001; Hamlin et al., 2004; Nakagawa et al., 2005) also contribute to the anxiety observed during early use. This suggests the need for a fundamental shift in thinking about the factors that contribute to the development of cocaine abuse. Although a complex multitude of behavioral, economic, and social factors undoubtedly motivate humans to ingest cocaine for the first time, the demonstration that laboratory animals will readily learn to self-administer the drug suggested to many that the primary motivation of organisms to maintain selfadministration behavior over time stems from the drug's positive reinforcing and/or rewarding properties (Wise and Bozarth, 1985; Deadwyler, 2010; Gardner, 2011). However, if indeed acute cocaine has both immediate positive and delayed negative effects from the very outset (as we and others have demonstrated), then the decision to ingest the drug a second time (and all subsequent times) should be viewed not in terms of the absolute magnitude of the drug's positive/rewarding properties, but rather as the relative "net" value of the experience for the organism when measured against the magnitude of the negative/anxiogenic properties of the drug. Indeed, it seems reasonable to suggest that individual differences in the development of cocaine abuse among those who have tried the drug may reflect individual differences in the relative value of the positive and negative experiences associated with initial drug exposure. From a neuroscience perspective, this would suggest that the development of cocaine self-administration depends upon the relative impact of cocaine on the circuitry mediating its rewarding effects versus the circuitry underlying cocaine's anxiogenic properties. Although cocaine reward has largely been attributed to dopaminergic neurotransmission within the mesocorticolimbic system (Wise, 1984; Carelli, 2002; Willuhn et al., 2010), the present study suggests that the aversive/ anxiogenic effects of the drug are at least in part attributable to NE neurotransmission within the CeA and BNST.

\section{References}

Anthony JC, Tien AY, Petronis KR (1989) Epidemiologic evidence on cocaine use and panic attacks. Am J Epidemiol 129:543-549. Medline

Aston-Jones G, Chiang C, Alexinsky T (1991) Discharge of noradrenergic locus coeruleus neurons in behaving rats and monkeys suggests a role in vigilance. Prog Brain Res 88;501-520. CrossRef Medline

Aston-Jones G, Delfs JM, Druhan J, Zhu Y (1999) The bed nucleus of the stria terminalis. A target site for noradrenergic actions in opiate withdrawal. Ann N Y Acad Sci 877;486-98. CrossRef Medline

Blanchard DC, Blanchard RJ (1999) Cocaine potentiates defensive behaviors related to fear and anxiety. Neurosci Biobehav Rev 23:981-991. CrossRef Medline

Carelli RM (2002) The nucleus accumbens and reward: neurophysiological investigations in behaving animals. Behav Cogn Neurosci Rev 1:281-296. CrossRef Medline

Carr GD, Fibiger HC, Phillips AG (1989) Conditioned place preference as a measure of drug reward. In: The neuropharmacological basis of reward (Liebman, JM and Cooper SJ, eds), pp 264-319. New York: Clarendon/ Oxford UP.

Cecchi M, Khoshbouei H, Javors M, Morilak DA (2002) a) Modulatory effects of norepinephrine in the lateral bed nucleus of the stria terminalis on behavioral and neuroendocrine responses to acute stress. Neuroscience 112:13-21. CrossRef Medline

Cecchi M, Khoshbouei H, Morilak DA (2002) b) Modulatory effects of norepinephrine, acting on alpha 1 receptors in the central nucleus of the amygdala, on behavioral and neuroendocrine responses to acute immobilization stress. Neuropharmacology 43:1139-1147. CrossRef Medline

Cohen A, Young RW, Velazquez MA, Groysman M, Noorbehesht K, BenShahar OM, Ettenberg A (2009) Anxiolytic effects of nicotine in a rodent test of approach-avoidance conflict. Psychopharmacology 204: 541-549. CrossRef Medline

Davis M (2006) Neural systems involved in fear and anxiety measured with fear-potentiated startle. Am Psychol 61:741-756. CrossRef Medline

Deadwyler SA (2010) Electrophysiological correlates of abused drugs: relation to natural rewards. Ann N Y Acad Sci 1187;140-47. CrossRef Medline

Ettenberg A (2004) Opponent process properties of self-administered cocaine. Neurosci Biobehav Rev 27:721-728. CrossRef Medline

Ettenberg A (2009) The runway model of drug self-administration. Pharmacol Biochem Behav 91:271-277. CrossRef Medline

Ettenberg A, Bernardi RE (2006) Anxiolytic-like actions of buspirone in a runway model of intravenous cocaine self-administration. Pharmacol Biochem Behav 85:393-399. CrossRef Medline

Ettenberg A, Bernardi RE (2007) Effects of buspirone on the immediate positive and delayed negative properties of intravenous cocaine as measured in the conditioned place preference test. Pharmacol Biochem Behav 87;171-8. CrossRef Medline

Ettenberg A, Geist TD (1991) Animal model for investigating the anx- 
iogenic effects of self-administered cocaine. Psychopharmacology 103: 455-461. CrossRef Medline

Ettenberg A, Geist TD (1993) Qualitative and quantitative differences in the operant runway behavior of rats working for cocaine and heroin reinforcement. Pharmacol Biochem Behav 44:191-198. CrossRef Medline

Ettenberg A, Raven MA, Danluck DA, Necessary BD (1999) Evidence for opponent-process actions of intravenous cocaine. Pharmacol Biochem Behav 64;507-12. CrossRef Medline

Galvez R, Mesches MH, McGaugh JL (1996) Norepinephrine release in the amygdala in response to footshock stimulation. Neurobiol Learn Mem 66:253-257. CrossRef Medline

Gardner EL (2011) Addiction and brain reward and antireward pathways. Adv Psychosom Med 30;22-60. CrossRef Medline

Geist TD, Ettenberg A (1990) A simple method for studying intravenous drug reinforcement in a runaway. Pharmacol Biochem Behav 36:703706. CrossRef Medline

Geist TD, Ettenberg A (1997) Concurrent positive and negative goalbox events produce runway behaviors comparable to those of cocaine-reinforced rats. Pharmacol Biochem Behav 57:145-150. CrossRef Medline

Gil M, Marti J, Armario A (1992) Inhibition of catecholamine synthesis depresses behavior of rats in the holeboard and forced swim tests: influence of previous chronic stress. Pharmacology, biochemistry and behavior 43:597-601. CrossRef Medline

Gracy KN, Dankiewicz LA, Koob GF (2001) Opiate withdrawal-induced fos immunoreactivity in the rat extended amygdala parallels the development of conditioned place aversion. Neuropsychopharmacology 24:152-160. CrossRef Medline

Guzman D, Ettenberg A (2004) Heroin attenuates the negative consequences of cocaine in a runway model of self-administration. Pharmacol Biochem Behav 79:317-324. CrossRef Medline

Hamlin AS, Buller KM, Day TA, Osborne PB (2004) Effect of naloxoneprecipitated morphine withdrawal on c-fos expression in rat corticotropinreleasing hormone neurons in the paraventricular hypothalamus and extended amygdala. Neurosci Lett 362:39-43. CrossRef Medline

Itoi K, Sugimoto N (2010) The brainstem noradrenergic systems in stress, anxiety and depression. J Neuroendocrinol 22:355-361. CrossRef Medline

Kilts CD, Anderson CM (1986) The simultaneous quantification of dopamine, norepinephrine and epinephrine in micropunched rat brain nuclei by on-line trace enrichment HPLC with electrochemical detection: Distribution of catecholamines in the limbic system. Neurochem Int 9:437445. CrossRef Medline

Knackstedt LA, Samimi MM, Ettenberg A (2002) Evidence for opponentprocess actions of intravenous cocaine and cocaethylene. Pharmacol Biochem Behav 72:931-936. CrossRef Medline

Koob GF, Le Moal M (1997) Drug abuse: hedonic homeostatic dysregulation. Science 278:52-58. CrossRef Medline

Leri F, Flores J, Rodaros D, Stewart J (2002) Blockade of stress-induced but not cocaine-induced reinstatement by infusion of noradrenergic antagonists into the bed nucleus of the stria terminalis or the central nucleus of the amygdala. J Neurosci 22:5713-5718. Medline

Miller NE (1944) Experimental studies of conflict. In: Personality and behavior disorders (Hunt I McV, ed), pp 431-465. New York: Ronald.

Moore RY, Bloom FE (1979) Central catecholamine neuron systems: anatomy and physiology of the norepinephrine and epinephrine systems. Annu Rev Neurosci 2:113-168. CrossRef Medline

Nakagawa T, Yamamoto R, Fujio M, Suzuki Y, Minami M, Satoh M, Kaneko S (2005) Involvement of the bed nucleus of the stria terminalis activated by the central nucleus of the amygdala in the negative affective component of morphine withdrawal in rats. Neuroscience 134:9-19. CrossRef Medline

Otis JM, Mueller D (2011) Inhibition of $\beta$-adrenergic receptors induces a persistent deficit in retrieval of a cocaine-associated memory providing protection against reinstatement. Neuropsychopharmacology 36:19121920. CrossRef Medline
Pacak K, McCarty R, Palkovits M, Kopin IJ, Goldstein DS (1995) Effects of immobilization on in vivo release of norepinephrine in the bed nucleus of the stria terminalis in conscious rats. Brain Res 688 (1-2);242-6.

Paxinos G, Watson C (2005) The rat brain in stereotaxic coordinates. New York: Elsevier Academic.

Phelix CF, Liposits Z, Paull WK (1992) Monoamine innervation of bed nucleus of stria terminalis: an electron microscopic investigation. Brain Res Bull 28:949-965. CrossRef Medline

Raven MA, Necessary BD, Danluck DA, Ettenberg A (2000) Comparison of the reinforcing and anxiogenic effects of intravenous cocaine and cocaethylene. Exp Clin Psychopharmacol 8:117-124. CrossRef Medline

Rogerio R, Takahashi RN (1992) Anxiogenic properties of cocaine in the rat evaluated with the elevated plus maze. Pharmacol Biochem Behav 43: 631-633. CrossRef Medline

Rudoy CA, Van Bockstaele EJ (2007) Betaxolol, a selective beta(1)adrenergic receptor antagonist, diminishes anxiety-like behavior during early withdrawal from chronic cocaine administration in rats. Prog Neuropsychopharmacol Biol Psychiatry 31:1119-1129. CrossRef Medline

Rudoy CA, Reyes AR, Van Bockstaele EJ (2009) Evidence for beta1adrenergic receptor involvement in amygdalar corticotropin-releasing factor gene expression: implications for cocaine withdrawal. Neuropsychopharmacology 34:1135-1148. CrossRef Medline

Schank JR, Liles LC, Weinshenker D (2008) Norepinephrine signaling through beta-adrenergic receptors is critical for expression of cocaineinduced anxiety. Biol Psychiatry 63:1007-1012. CrossRef Medline

Schweimer J, Fendt M, Schnitzler HU (2005) Effects of clonidine injections into the bed nucleus of the stria terminalis on fear and anxiety behavior in rats. Eur J Pharmacol 507;117-124. CrossRef Medline

Shaham Y, Shalev U, Lu L, De Wit H, Stewart J (2003) The reinstatement model of drug relapse: history, methodology and major findings. Psychopharmacology 168(1-2);3-20.

Smith RJ, Aston Jones G (2008) Noradrenergic transmission in the extended amygdala: role in increased drug-seeking and relapse during protracted drug abstinence. Brain Struct Funct 213(1-2);43-61.

Stone EA, Manavalan SJ, Zhang Y, Quartermain D (1995) Beta adrenoceptor blockade mimics effects of stress on motor activity in mice. Neuropsychopharmacology 12:65-71. Medline

Su Z, Wenzel J, Ettenberg A, Ben-Shahar O (2013) Prior extended daily access to cocaine elevates the reward threshold in a conditioned place preference test. Addict Biol, in press.

van Stegeren AH (2008) The role of the noradrenergic system in emotional memory. Acta Psychol (Amst) 127:532-541. CrossRef Medline

Watanabe T, Nakagawa T, Yamamoto R, Maeda A, Minami M, Satoh M (2003) Involvement of noradrenergic system within the central nucleus of the amygdala in naloxone-precipitated morphine withdrawal-induced conditioned place aversion in rats. Psychopharmacology 170:80-88. CrossRef Medline

Wenzel JM, Waldroup SA, Haber ZM, Su ZI, Ben-Shahar O, Ettenberg A (2011) Effects of lidocaine-induced inactivation of the bed nucleus of the stria terminalis, the central or the basolateral nucleus of the amygdala on the opponent-process actions of self-administered cocaine in rats. Psychopharmacology 217:221-230. CrossRef Medline

Williamson S, Gossop M, Powis B, Griffiths P, Fountain J, Strang J (1997) Adverse effects of stimulant drugs in a community sample of drug users. Drug Alcohol Depend 44:87-94. CrossRef Medline

Willuhn I, Wanat MJ, Clark JJ, Phillips PE (2010) Dopamine signaling in the nucleus accumbens of animals self-administering drugs of abuse. Curr Top Behav Neurosci 3;29-71. CrossRef Medline

Wise RA (1984) Neural mechanisms of the reinforcing action of cocaine. NIDA Res Monogr 50;15-33. Medline

Wise RA, Bozarth MA (1985) Brain mechanisms of drug reward and euphoria. Psychiatr Med 3:445-460. Medline 